\title{
Physical and chemical properties of pyropheophorbide-a methyl ester in ethanol, phosphate buffer and aqueous dispersion of small unilamellar dimyristoyl-L- $\alpha$-phosphatidylcholine vesicles
}

\author{
Lisiane Delanaye, ${ }^{\text {,a }}$ Mohamed Ali Bahri, ${ }^{\mathrm{b}}$ Francis Tfibel, ${ }^{\mathrm{c}}$ Marie-Pierre Fontaine-Aupart, ${ }^{\mathrm{c}}$ Ange Mouithys- \\ Mickalad, ${ }^{\mathrm{d}}$ Bélinda Heine, ${ }^{\mathrm{a}}$ Jacques Piette $^{\mathrm{e}}$ and Maryse Hoebeke ${ }^{\mathrm{a}}$ \\ ${ }^{a}$ Biomedical Spectroscopy, Department of Physics, B5, University of Liège, B-4000 Liège, Belgium; E-mail: \\ lisiane.delanaye@ulg.ac.be \\ ${ }^{b}$ Laboratory of Experimental Medical Imaging, Institute of Physics, B5, University of Liège, B-4000 Liège, \\ Belgium \\ ${ }^{c}$ Laboratory of Molecular Photophysics, UPR 3361 CNRS, Federation LUMAT, University of Paris-Sud, 91405 \\ Orsay, France \\ ${ }^{d}$ Centre for oxygen, R.\& D. (C.O.R.D.), Institute of Chemistry, University of Liège, B6a, B-4000 Liège, Belgium \\ ${ }^{e}$ Laboratory of Virology and Immunology, Institute of Pathology, B23, University of Liège, B-4000 Liège, Belgium
}

This submission was created using the RSC Article Template (DO NOT DELETE THIS TEXT) (LINE INCLUDED FOR SPACING ONLY - DO NOT DELETE THIS TEXT)

The aggregation process of pyropheophorbide-a methyl ester (PPME), a second generation photosensitizer, was investigated in various solvents. Absorption and fluorescence spectra showed that the photosensitizer was under a monomeric form in ethanol as well as in dimyristoyl-L- $\alpha$-phosphatidylcholine liposomes while it was strongly aggregated in phosphate buffer. A quantitative determination of reactive oxygen species production by PPME in these solvents has been undertaken by electron spin resonance associated with spin trapping technique and absorption spectroscopy. In phosphate buffer, both electron spin resonance and absorption measurements led to the conclusion that singlet oxygen production was not detectable while hydroxyl radical production was very weak. In liposomes and ethanol, singlet oxygen and hydroxyl radical production increased highly; the singlet oxygen quantum yield was determined to be 0.2 in ethanol and 0.13 in liposomes. The hydroxyl radical production origin was also investigated. Singlet oxygen was formed from PPME triplet state deactivation in presence of oxygen. Indeed, the triplet state formation quantum yield of PPME was found to be about 0.23 in ethanol, 0.15 in liposomes (too small to be measured in PBS).

\section{Introduction}

Photodynamic therapy (PDT) is a performent treatment for cancer $^{1,2,3}$ and other non-oncological diseases such as psoriasis ${ }^{4}$. It is characterized by the concommitant use of a photosensitizing agent (the photosensitizer) and light above $600 \mathrm{~nm}$ where the endogenous tissular components are more transparent to the incident radiation ${ }^{5,6}$. The excited photosensitizer interacts with surrounding oxygen to create active forms of oxygen called reactive oxygen species (ROS) believed to be responsible for the cytotoxic action of PDT.

The first photosensitizer approved for PDT was the Photofrin which presents several drawbacks like a low absorbance at 630 $\mathrm{nm}$, poor tumor selectivity and prolonged skin sensitivity. These drawbacks led to the development of second-generation photosensitizers. The properties of chlorophyll $a$ make this compound and its derivatives good candidates as photosensitizers ${ }^{7}$. Among them, pheophorbide-a which presents selective accumulation in tumors, small toxicity and a photoxicity on tumor cells which can be 20 -fold more efficient than hematoporphyrin derivatives ${ }^{8}$. The major advantages of pheophorbides are their absorption maximum around $660 \mathrm{~nm}$ and their monomeric state in organic solvents ${ }^{9}$. A series of effective photosensitizers derived from pheophorbide-a were synthesized since 1985. They exhibited biological properties (localization, cytotoxicity, and elimination) more interesting for their use in PDT than pheophorbide- $\mathrm{a}^{10}$. For example, the pyropheophorbides are more stable because of the loss of the ester fonction. Their photosensitizing efficaciency increases with the length of the alkyl ether side-chain ${ }^{11}$. They have similar photophysical properties (singlet oxygen and fluorescence yields) as the parent compound but conformation of the alkyl side chains as well as hydrophobicity influence localization in the cells.

In view of its potential use in the PDT of cancer, pyropheophorbide-a methyl ester (PPME) is an attractive second-generation photosensitizer ${ }^{12,13,14}$. The structure of PPME differs from that of chlorophyll-a (Fig.1) in the loss of the magnesium in the center of the molecule, the substitution of the phytol group $\left(\mathrm{H}_{39} \mathrm{C}_{20}\right)$ by methyl $\left(\mathrm{CH}_{3}\right)$ and the loss of a carbomethoxy group $\left(-\mathrm{COOCH}_{3}\right)$ at $\mathrm{C}_{10}$ of the isocyclic ring.

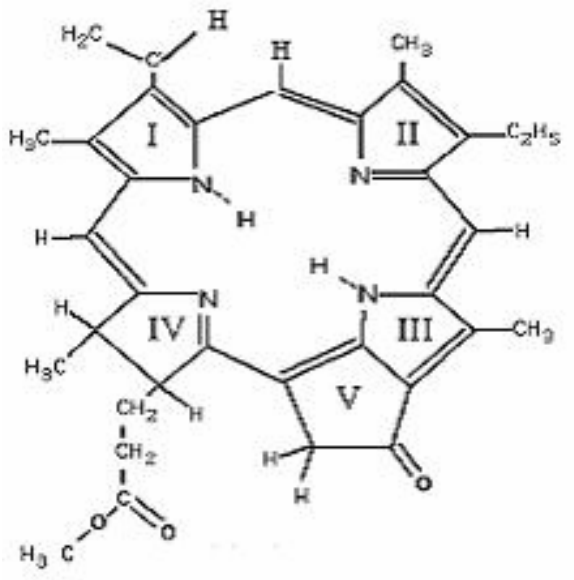

Fig.1 Structure of PPME. 
This photosensitizer has two strong absorption maxima at 410 and $666 \mathrm{~nm}$, in acetone. The molar extinction coefficient of $\operatorname{PPME}\left(\varepsilon_{666 \mathrm{~nm}}=4.75 \times 10^{4} \mathrm{M}^{-1} \mathrm{~cm}^{-1}\right)^{13}$ is about half that of chlorophyll-a in acetone $\left(\varepsilon_{662 \mathrm{~nm}}=8.0-8.8 \times 10^{4} \mathrm{M}^{-1} \mathrm{~cm}^{-1}\right)$ probably because of the loss of magnesium and carbomethoxy group. The loss of the metal ions in the center of the molecule ${ }^{15}$ as well as the hydrophobicity ${ }^{16}$ seem to decrease the photosensitizing activity. The phototoactivation of porphyrins and their analogues (chlorins, porphycenes, purpurins, phthalocyanines and naphthalocyanines) can be increased by the insertion of metal ions into the center of the ring ${ }^{17}$. These porphyrin derivatives displayed absorption bands peaking at longer wavelengths and showing larger molar extinction coefficients as compared with porphyrins. Such spectroscopic properties were important since they guaranteed a higher probability and efficiency of light absorption. Indeed, lifetime of the triplet state, triplet state quantum yield and singlet oxygen quantum yield were enhanced by this modification. The use of liposomes can also improve the photosensitizer efficiency.

In general, during PDT, the tumour is mainly destroyed by the ROS ${ }^{18,19}$. Singlet oxygen $\left({ }^{1} \mathrm{O}_{2}\right)$ is considered as the most important cytotoxic agent involved in $\mathrm{PDT}^{20,21}$. However, the biological damage might be due to other ROS such as superoxide anion $\left(\mathrm{O}_{2}^{-{ }^{-}}\right)$and hydroxyl radicals $\left({ }^{\circ} \mathrm{OH}\right)$. In the presence of oxygen two types of mechanisms are possible ${ }^{22}$. Indeed, the excited sensitizer can react with the substrate or solvent (mechanism Type I) or with oxygen (mechanism Type II) to form in this case ${ }^{1} \mathrm{O}_{2}$. The Type I reaction is due to either electron or proton transfers leading to the generation of radicals. As demonstrated previously ${ }^{12},{ }^{1} \mathrm{O}_{2}$ produced by photoexcited PPME is involved in the necrosis of colon cancer cells (HCT116) but photoexcited PPME can also trigger apoptosis of tumoral cells mediated by ${ }^{\circ} \mathrm{OH}$ or $\mathrm{O}_{2}{ }^{-}$. In vivo however, it is difficult to draw conclusions on the exact mechanisms which induce tumour death, because the reaction pathway depends on the oxygenation of the tumor ${ }^{23,24}$, the ${ }^{1} \mathrm{O}_{2}$ lifetime in the particular environment ${ }^{25,26}$ and the stability of the generated radicals ${ }^{27}$. Type I mechanisms are predominant in polar media while type II mechanisms are predominant in hydrophobic environments $^{27,28}$. Thus, the mechanisms (type I or type II) of cell destruction depend on the localization of the sensitizer because it was shown that the photosensitizer localization in cancer cells is related to its lipophilic or hydrophobic character ${ }^{29}$. Consequently, we have detailed the aggregation process of PPME and the consequences on its ROS production. The study was carried out in ethanol, aqueous solutions of phosphate buffer (PBS) but also in aqueous dispersion of small unilamellar dimyristoyl-L- $\alpha$-phosphatidylcholine (DMPC) vesicles. Indeed, to enhance the efficacy of PDT, liposomes come into focus as a valuable carrier and delivery system, particularly for hydrophobic photosensitizers ${ }^{30}$. Using absorption and fluorescence spectroscopy, it was shown that PPME is in a monomeric form in ethanol and liposomes but strongly aggregated in PBS. We also studied by transient absorption spectroscopy and electron spin resonance (ESR) associated with the spin trapping method, the effect of the aggregation state of the irradiated photosensitizer on its ROS production. Since singlet oxygen is initially formed by energy transfer from the excited triplet state of the photosensitizer to ground-state oxygen, the triplet state properties of PPME were investigated using by laser flash photolysis experiments in these three solvents.

\section{Materials and methods}

\section{Sample preparation}

A stock solution of PPME (Sigma Belgium, $95 \%$ purity) was made in ethanol $(50 \mu \mathrm{M})$ and kept in the dark at $-20^{\circ} \mathrm{C}$. PPME aqueous solutions were prepared by dilution of this ethanolic stock solution in such way that the final ethanol concentration did not exceed $10 \%$, except for ESR measurements in which case $20 \%$ of ethanol was used. The sample was kept in the dark at $25^{\circ} \mathrm{C}$. To study ${ }^{1} \mathrm{O}_{2}$ production from irradiated PPME, we used 9,10 dimethylanthracene (DMA), anthracene-9,10diproprionic acid (ADPA), sodium azide $\left(\mathrm{NaN}_{3}\right)$ and rose bengal (RB) from Sigma. The ROS formation was monitored using 5,5dimethyl-1-pyrroline-N-oxide (DMPO), sodium benzoate, 2,2,6,6-tetramethyl-4-piperidone (4-oxo-TEMP), superoxide dismutase (SOD, bovine erythrocytes) and desferrioxamine from Sigma.

Unilamellar liposomes were prepared using an extrusion procedure as described previously ${ }^{31,32}$. DMPC (from Sigma) was dissolved in chloroform $(25 \mathrm{mg} / 5 \mathrm{ml}$, HPLC grade) and the solution was evapored for $30 \mathrm{~min}$. For ESR, PPME, n-doxyl stearic acid spin probe (n-DSA) and DMA were dissolved with lipids before evaporation. In that case, the evaporation time was for $1 \mathrm{~h} 30$ at least. Multilamellar vesicles (MLV) were prepared by mechanical stirring (vortex mixer) of the lipid film suspended in PBS $(\mathrm{pH}=7.00)$ at a temperature above $23.9^{\circ} \mathrm{C}$, the DMPC phase transition temperature. To improve incorporation of PPME into liposomes, 5 cycles of freezing-unfreezing of the solution were performed by plunging the solution into liquid nitrogen and then into water at a temperature above the DMPC phase transition temperature. Unilamellar liposomes were formed by extrusion of the suspension through polycarbonate filters $(0.1$ $\mu \mathrm{m}$ pore size, Nucleopores, Pleasanton, CA) using a commercial extruder apparatus thermostated at a temperature above the phase-transition temperature of the phospholipids. The procedure was repeated 10 times and induced unilamellar liposomes with a mean size of about $90 \mathrm{~nm}$ diameter. Liposomes were prepared at a lipid concentration of $7.4 \mathrm{mM}$. To remain in the aqueous core, SOD and desferrioxamine was incorporated to the multilamellar liposomes before the 5 cycles of freezing-unfreezing.

\section{Determination of PPME incorporation limit in liposomes}

In the presence of DMPC liposomes, PPME partition properties

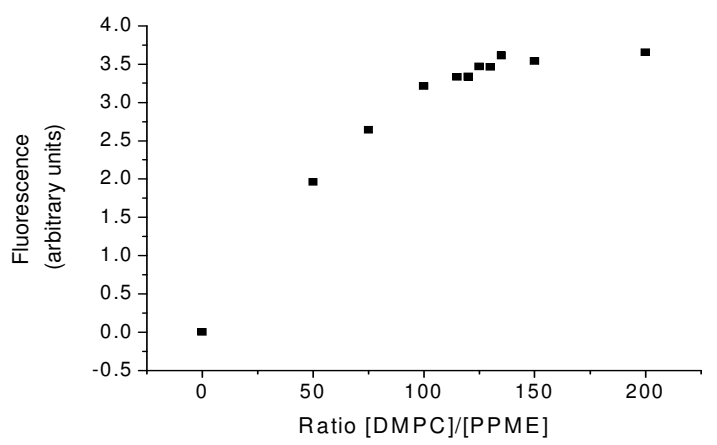

Fig.2 Influence of DMPC concentration on fluorescence emission of $\operatorname{PPME}(2.5 \mu \mathrm{M})$ at $681 \mathrm{~nm}\left(\right.$ at $\left.26^{\circ} \mathrm{C}\right)$.

between lipid bilayers and water aqueous phase were monitored by recording absorption and fluorescence spectra of selected solutions made with various lipids concentrations at constant PPME concentration. In general, incorporation of a dye in liposomes led to an increase of the fluorescence intensity in comparison with its intensity in aqueous solutions. This increase was studied as a function of the lipid concentration at constant PPME concentration $(2.5 \mu \mathrm{M})$ in order to establish the ratio between lipids and dye at which all PPME in suspension may be considered as bound to liposomes ${ }^{33}$. Fig. 2 shows the evolution of PPME fluorescence $\left(2.5 \mu \mathrm{M}, 26^{\circ} \mathrm{C}\right)$ at $681 \mathrm{~nm}$ in the presence of increasing lipids concentrations. When the total lipid concentration was increased above $0.34 \mathrm{mM}$, the emission fluorescence reached a maximum corresponding to total PPME 
incorporation inside the liposomes. Under the present experimental conditions, this corresponds to a lipid to PPME ratio of 135 at $26^{\circ} \mathrm{C}$.

\section{Fluorescence, absorption measurements and electron spin resonance spectroscopy}

The absorption spectra were recorded using a Kontron double beam spectrophotometer (Uvikon 941). The solutions were placed in a quartz (Suprasil) cell $(0.4 \mathrm{~cm}$ width $\mathrm{x} 1 \mathrm{~cm}$ path length, Hellma, Belgium) except for PPME solutions in PBS where the cell used had a $10 \mathrm{~cm}$ path length. The fluorescence measurements were carried out on a SLM-Aminco 500 spectrofluorimeter (SLM instruments).

The ESR measurements were performed at $9.56 \mathrm{GHz}$ with a Bruker ESP 300E spectrometer equipped with a variable temperature controler accessory locked at a constant temperature above the DMPC transition temperature. Measurements were performed by using a $50-\mathrm{G}$ scan range at $20 \mathrm{~mW}$ microwave power and 1-G modulation amplitude for experiments with liposomes and 2-G modulation amplitude for PBS experiments. The solution was irradiated directly inside the microwave cavity of the spectrometer.

The irradiation of the samples was realized in air using a spotlight Pradovit RA $150 \mathrm{~W}$ (Leitz) with a cut-off filter which eliminate light under $630 \mathrm{~nm}$. The RB needed a $475 \mathrm{~nm}$ cut-off filter.

The stearic acid spin labels were dissolved with DMPC in chloroform before drying the solution under vacuum. The molar ratio of label to lipid was 0.01 to ensure complete intercalation of 5-, 7-, 12-, 16-DSA in the membrane ${ }^{34}$.

\section{Nanosecond laser flash photolysis}

Nanosecond absorption measurements were carried out using a laser photolysis equipment described previously ${ }^{35,36}$. Briefly, the excitation source was a Q-switched Nd/YAG laser (Quantel YG $441)$ of $2 \mathrm{~ns}$ full width at half maximum with third harmonic $(355 \mathrm{~nm})$ generation. The $355 \mathrm{~nm}$ beam was directed onto one side of a square silica cell containing the sample. The variations were monitored at right angles to the excitation in a crossbeam arrangement using a xenon flash lamp, a monochromator, a photomultiplier and a digitized oscilloscope interfaced with a microcomputer. The time and the spectral resolutions of this setup were $2 \mathrm{~ns}$ and $1 \mathrm{~nm}$, respectively.

The triplet quantum yield of PPME was determined using a comparative method ${ }^{37,38}$. In this method, anthracene in deaerated cyclohexane was used as reference according to the following equation :

$$
\Phi_{\mathrm{T}}^{\mathrm{PPME}}=\Phi_{\mathrm{T}}^{\text {Anthracene }} \frac{\Delta \mathrm{A}_{\mathrm{T}}^{\mathrm{PPME}}\left(\varepsilon_{\mathrm{T}}^{\text {Anthracene }}-\varepsilon_{\mathrm{F}}^{\text {Anthracene }}\right)}{\Delta \mathrm{A}_{\mathrm{T}}^{\text {Anthracene }}{ }_{\left(\varepsilon_{\mathrm{T}}^{\mathrm{PPME}}-\varepsilon_{\mathrm{F}}^{\mathrm{PPME}}\right)}}
$$

where $\Phi_{\mathrm{T}}{ }^{\text {Anthracene }}$ and $\Phi_{\mathrm{T}}{ }^{\text {PPME }}$ are the triplet quantum yields for anthracene and PPME, respectively, $\triangle \mathrm{A}_{\mathrm{T}}^{\text {Anthracene }}$ and $\Delta \mathrm{A}_{\mathrm{T}}^{\mathrm{PPME}}$ are the absorbance variations measured just after the laser pulse, due to the formation of the triplet state for anthracene and PPME respectively, $\varepsilon_{\mathrm{T}}^{\text {Anthracene }}$ and $\varepsilon_{\mathrm{T}}^{\mathrm{PPME}}$ the respective triplet molar extinction coefficients, $\varepsilon_{\mathrm{F}}$ Anthracene and $\varepsilon_{\mathrm{F}}$ PPE the respective ground state molar extinction coefficients. This method of determining quantum yields is valid if only a small fraction of the molecules are excited so that the absorbance change obtained remains linear with the laser energy ${ }^{37,38} \cdot \varepsilon_{\mathrm{F}}^{\mathrm{PPE}}$ at $450 \mathrm{~nm}$ is equal to $3300 \mathrm{M}^{-1} \mathrm{~cm}^{-1}$ and $\varepsilon_{\mathrm{F}}{ }^{\text {Anthracene }}$ is equal to 0 at $422 \mathrm{~nm}$. The triplet quantum yield value of anthracene was taken as $0.71^{37,38}$.

\section{Singlet oxygen production during PPME irradiation}

To study the production and diffusion of ${ }^{1} \mathrm{O}_{2}$ generated by photoexcited PPME, the oxidation of a specific ${ }^{1} \mathrm{O}_{2}$-scavenging agent, the substrate (A), was followed by absorption spectroscopy. DMA was chosen for the experiments in ethanol and liposomes and ADPA in PBS for solubilization reasons.

The absolute value of the singlet oxygen quantum yield of

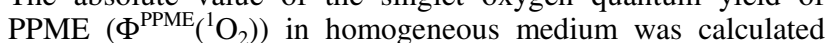
using $\mathrm{RB}$ as standard $\left(\Phi^{\mathrm{RB}}\left({ }^{1} \mathrm{O}_{2}\right)\right.$ is 0.86 in ethanol). In the presence of the substrate, ${ }^{1} \mathrm{O}_{2}$ generated by a photosensitizer (Sens) upon continuous stationary irradiation undergoes several decay processes ${ }^{28,39}$. According to literature ${ }^{40}$,

$$
\frac{\mathrm{d}[\mathrm{A}]}{\mathrm{dt}}=-\mathrm{k}_{\mathrm{S}}[\mathrm{A}] \text { and } \ln [\mathrm{A}]=\ln [\mathrm{A}]_{0}-\mathrm{k}_{\mathrm{S}} \mathrm{t}
$$

With

$$
\mathrm{k}_{\mathrm{S}}=\mathrm{I} \Phi\left({ }^{1} \mathrm{O}_{2}\right) \frac{\mathrm{k}_{\mathrm{r}}}{\mathrm{k}_{\mathrm{d}}+\left(k_{r}+k_{p}\right)[A]}
$$

where $\mathrm{I}$ is the light intensity absorbed by the photosensitizer, $\mathrm{k}_{\mathrm{r}}$ is the rate constant of the substrate oxidation by ${ }^{1} \mathrm{O}_{2}, \mathrm{k}_{\mathrm{d}}$, the rate constant of singlet oxygen deactivation by the solvent and $\mathrm{k}_{\mathrm{p}}$, the rate constant of ${ }^{1} \mathrm{O}_{2}$ physical quenching by $A$. In our experiments, $\left(k_{r}+k_{p}\right)[A]$ may be negliged compared to $k_{d} \cdot k_{s}$ became :

$$
\mathrm{k}_{\mathrm{S}}=\mathrm{I} \Phi\left({ }^{1} \mathrm{O}_{2}\right) \frac{\mathrm{k}_{\mathrm{r}}}{\mathrm{k}_{\mathrm{d}}}
$$

$\Phi^{\mathrm{PPME}}\left({ }^{1} \mathrm{O}_{2}\right)$ can be obtained using the equation :

$$
\Phi^{\mathrm{PPME}}\left({ }^{1} \mathrm{O}_{2}\right)=\Phi^{\mathrm{RB}}\left({ }^{1} \mathrm{O}_{2}\right) \frac{\mathrm{k}_{\mathrm{s}, \mathrm{PPME}}}{\mathrm{k}_{\mathrm{s}, \mathrm{RB}}} \frac{\mathrm{I}^{\mathrm{RB}}}{\mathrm{I}^{\mathrm{PPME}}}
$$

where $\mathrm{I}^{\mathrm{RB}}$ and $\mathrm{I}^{\mathrm{PPME}}$ are the total light intensities absorbed by RB and PPME respectively and $\mathrm{k}_{\mathrm{s}}, \mathrm{RB}$ or $\mathrm{k}_{\mathrm{s}}$,PPME are the slopes of the kinetics of the substrate disappearance photosensitized by either $\mathrm{RB}$ or PPME.

In DMPC liposomes, ${ }^{1} \mathrm{O}_{2}$ produced by photoexcited PPME solubilized in the lipidic bilayer $\left([\mathrm{PPME}]=10^{-5} \mathrm{M}\right.$, [liposomes $]=$ $\left.7.38 \times 10^{-3} \mathrm{M}\right)$, can diffuse through liposomes ${ }^{39}$. The technique used to determine $\Phi^{\mathrm{PPME}}\left({ }^{1} \mathrm{O}_{2}\right)$ was the same than in homogeneous solvents but the rate of ${ }^{1} \mathrm{O}_{2}$ deactivation by the solvent, $\mathrm{k}_{\mathrm{d}}$, was represented, taking into account the heterogeneity of the environment ${ }^{38}$ by

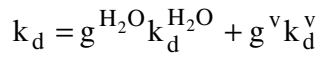

where $\mathrm{k}_{\mathrm{d}}{ }^{\mathrm{H} 20}$ and $\mathrm{k}_{\mathrm{d}}{ }^{\mathrm{v}}$ are, respectively, the partial constants for ${ }^{1} \mathrm{O}_{2}$ quenching in water and in the vesicle phase and $\mathrm{g}_{2} \mathrm{H}_{2}$ and $\mathrm{g}^{\mathrm{v}}$ are the corresponding weighting factors related by

$$
\mathrm{g}_{2}^{\mathrm{H} \mathrm{O}}+\mathrm{g}^{\mathrm{v}}=1
$$

The rate of DMA photobleaching due to irradiation of the photosensitizer in liposomes is given by :

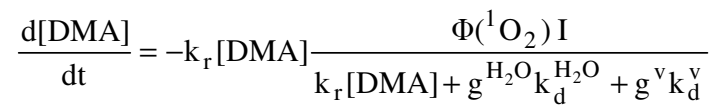


If the kinetics is first order, we can simplify the previous equation

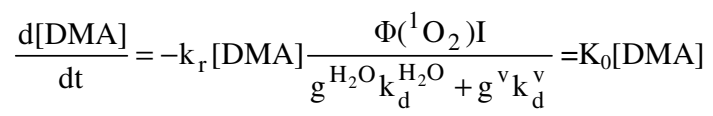

To determine the values of the weighting factors, isotopic lifetime enhancement by solvent deuteration was used ${ }^{40} . \Phi\left({ }^{1} \mathrm{O}_{2}\right)$ in liposomes can be calculated in the same way than in homogeneous solvent using $\Phi^{\mathrm{PPME}}\left({ }^{1} \mathrm{O}_{2}\right)$ in ethanol as a reference yield :

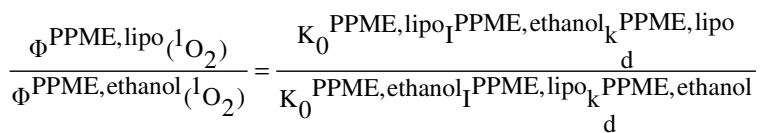

\section{RESULTS}

\section{Aggregation process}

At room temperature, pheophorbides are monomeric in organic solvents $^{9}$ and aggregated in polar solvents particular in aqueous solutions ${ }^{41}$. This properties is of importance due to its relation with the photodynamic activity of hydrophobic photosensitizers $^{39}$. It is thus of importance to detail the aggregation properties of PPME. The experiments have been undertaken in three different medium ethanol, aqueous solutions of phosphate buffer and DMPC liposomes.

The absorption spectrum of PPME in ethanol is typical of pyropheophorbides $^{42}$ with two main absorption bands centred at $410 \mathrm{~nm}$ (molar extinction coefficient $97000 \mathrm{M}^{-1} \mathrm{~cm}^{-1}$ ) and 666 $\mathrm{nm}$ (molar extinction coefficient $48000 \mathrm{M}^{-1} \mathrm{~cm}^{-1}$ ) and three weaker peaks with maxima at 508, 538 and $609 \mathrm{~nm}$ respectively (Fig. 3A). PPME solutions in ethanol followed the Beer-Lambert law up to $50 \mu \mathrm{M}$, revealing that PPME is monomeric under such conditions $^{33}$. PPME has a fluorescence maximum in ethanol at $676 \mathrm{~nm}$ (Fig. 3B). The fluorescence spectra of PPME in PBS and DMPC liposomes are similar to that in ethanol but with a $5 \mathrm{~nm}$ red shift.

The shape of the absorption spectrum of PPME in PBS depended on the photosensitizer concentration. By comparison with the PPME aborption spectrum in ethanol, both an absorption decrease, a spectral broadening and a bathochromic shift of the PPME absorption bands were observed. These changes were assigned to aggregates formation, which was confirmed by the strong quenching of the dye fluorescence.

The increase of a lipid concentration ranging from $0 \mathrm{mM}$ to 0.34 $\mathrm{mM}$ for a constant PPME concentration of $2.5 \mu \mathrm{M}$ induced a red shift of the absorption spectra peak at $668 \mathrm{~nm}$ towards $672 \mathrm{~nm}$ (data not shown). In a vesicle suspension, in which all drug molecules were bound to the bilayers, the addition of photosensitizer-unbound molecules resulted in a spectrum which was the superposition of PPME spectrum in water and PPME spectrum in DMPC liposomes. Above $0.34 \mathrm{mM}$ lipid concentration, no further shift was observed. Under these conditions, PPME $(2 \mu \mathrm{M})$ in DMPC liposomes $(0.5 \mathrm{mM})$, represented in Fig.3A, was completely incorporated in the bilayer. The shape of this absorption spectrum did not vary with PPME concentrations in the range $0.5 \mu \mathrm{M}-3.5 \mu \mathrm{M}$ at a constant lipid concentration of $0.5 \mathrm{mM}$ revealing that PPME was also under a single form in liposomes, with a molar extinction coefficient of $41000 \mathrm{M}^{-1} \mathrm{~cm}^{-1} \pm 10 \%$ at $672 \mathrm{~nm}$. The shape of the absorption spectrum was similar that in ethanol (Fig. 3A) with only a red shift of $6 \mathrm{~nm}$ of the different peaks.
A)

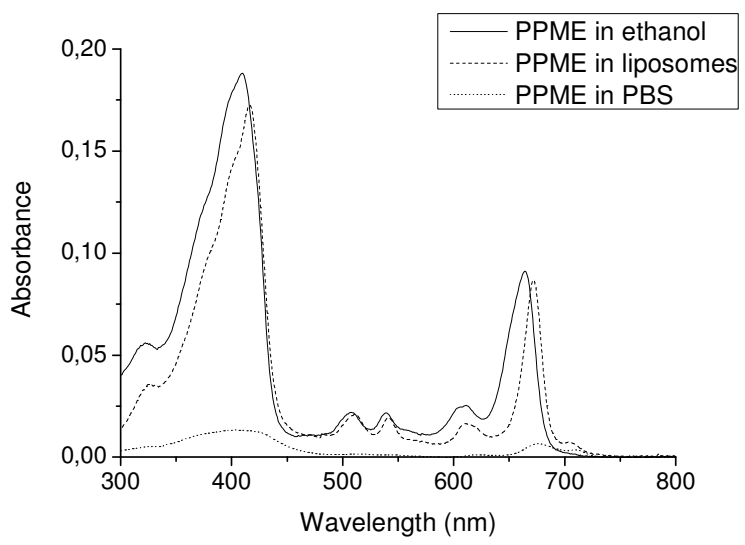

B)

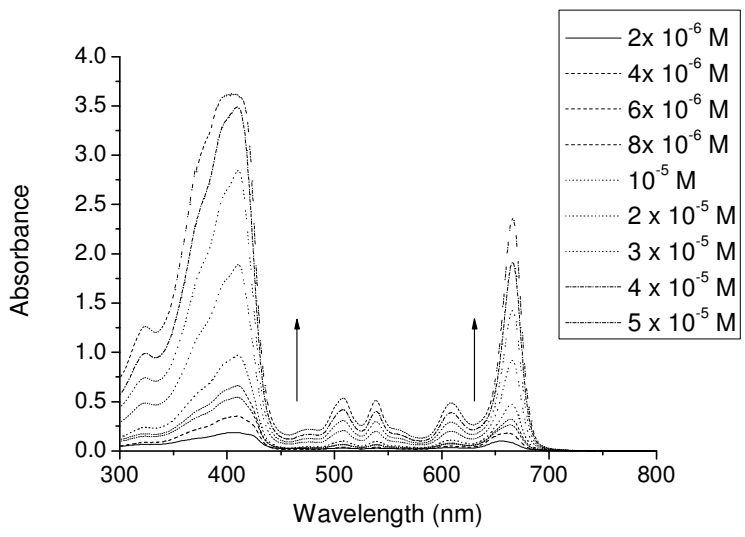

C)

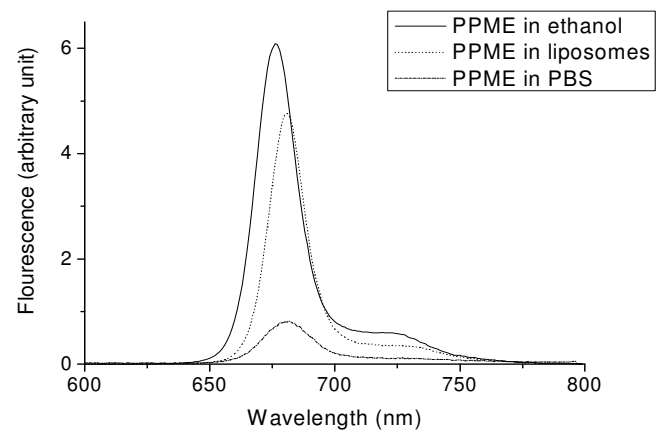

Fig.3 A) Absorption spectra of PPME $(2 \mu \mathrm{M})$ in ethanol, phosphate buffer $(\mathrm{pH}=7.00)$ and liposomes. B) Absorption spectra of PPME in PBS at different concentrations. C) Fluorescence spectra of PPME $(2 \mu \mathrm{M})$ in ethanol, liposomes and PBS. 


\section{PPME localization in liposomes}

In order to compare the rates of n-DSA ESR signal decay in a homogeneous solvent due to PPME irradiation, four spin-labeled stearic acids having their nitroxyl group at various positions $\left(\mathrm{C}_{5}\right.$, $\mathrm{C}_{7}, \mathrm{C}_{12}, \mathrm{C}_{16}$ ) among the carbon chain were used. In the bilayers, the four spin labels were oriented with their long axes parallel to the phospholipid chains yielding informations on the environment of the $\mathrm{C}_{5}, \mathrm{C}_{7}, \mathrm{C}_{12}, \mathrm{C}_{16}$ carbon respectively. The interaction between PPME and n-DSA was first examined in ethanol. The ESR spectra of the stearic acid spin probes dissolved in ethanol consisted of three symmetric absorption lines (data not shown). In a $\mathrm{N}_{2}$-saturated ethanol solution

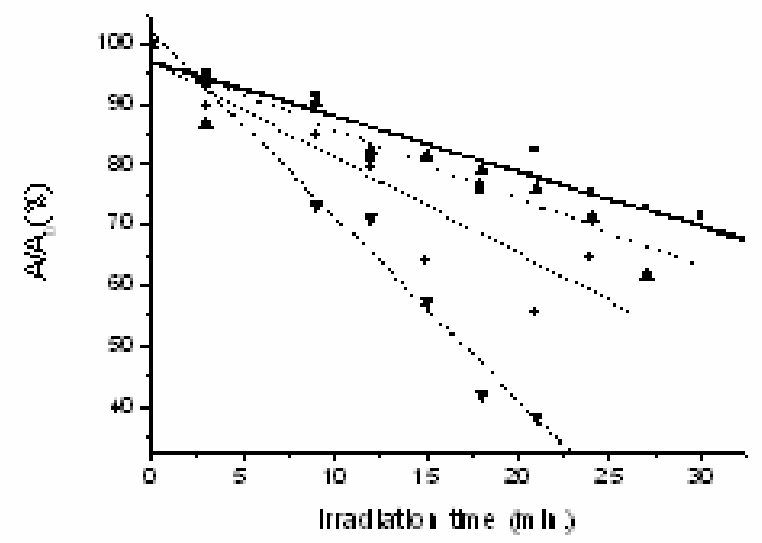

Fig 4 Decrease of the n-DSA cancentration (-: 16-DSA $*$ : 5-DS.

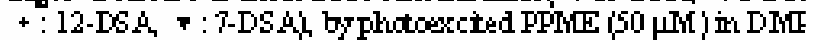
liposanes (7.4 mil is a finction of the illmination time. Tr samples nere bubbled wifh nirogen $A / A$ derotes the sign amplinde af nitraxide relative to the amplinde at time zero.

containing $50 \mu \mathrm{M}$ PPME and $70 \mu \mathrm{M}$ n-DSA, the irradiation of the solution caused a slow decrease of the amplitude of the ESR signal. The decay rate was first order and was dependent on PPME concentration. No variation of the n-DSA signal amplitude was observed in the absence of PPME or irradiation. PPME can thus transfer an electron to n-DSA whose ESR signal decreased $^{34}$. The amplitude of the ESR signal decay was the same for all n-DSA.

The ESR signal amplitude of n-DSA incorporated in liposomes disappeared by irradiation in the presence of PPME (Figure 4). The rates of the process followed first order kinetics and in the order : 7-DSA $>12-D S A>5-D S A>16-D S A$. Like in ethanol, PPME transfered an electron to n-DSA as well on 5, 7, 12 or 16 carbon. Fig. 4 shows that PPME is completely localized in the liposomes bilayer whatever depths ${ }^{34}$.

\section{Reactive Oxygen Species (ROS) production}

To characterize the production of free radicals following the irradiation of PPME in liposomes and PBS, the ESR spin trapping technique was used ${ }^{43}$. DMPO was chosen as a spin trap. Irradiation of PPME in liposomes with red light $(\lambda>650 \mathrm{~nm})$ in the presence of DMPO $(50 \mathrm{mM})$ produced a four - line ESR spectrum with hyperfine splittings $\left(\mathrm{a}^{\mathrm{N}}=\mathrm{a}^{\mathrm{H}}=14.9 \mathrm{G}\right)$ characteristic of the DMPO-OH spin adduct (Fig.5A). No signal was observed without irradiation.

The addition of $0.1 \mathrm{M}$ sodium benzoate, hydroxyl radical $\left({ }^{\circ} \mathrm{OH}\right)$ quencher, abolished the ESR signal of DMPO-OH adduct (75 $\%$ of reduction) as shown on Fig 5A. The addition of water soluble ADPA, an ${ }^{1} \mathrm{O}_{2}$ quencher, led also to a signal reduction but only of $16 \%$. The use of $0.6 \mathrm{mM}$ DMA $\left({ }^{1} \mathrm{O}_{2}\right.$ quencher, inside liposomes) led to $10 \%$ reduction of the ESR signal. Moreover, in presence of sodium benzoate $(0.1 \mathrm{M})$, ADPA $(7.5 \mu \mathrm{M})$ and
A)

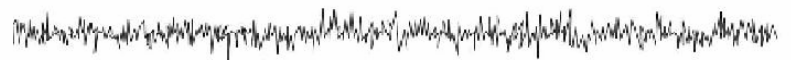

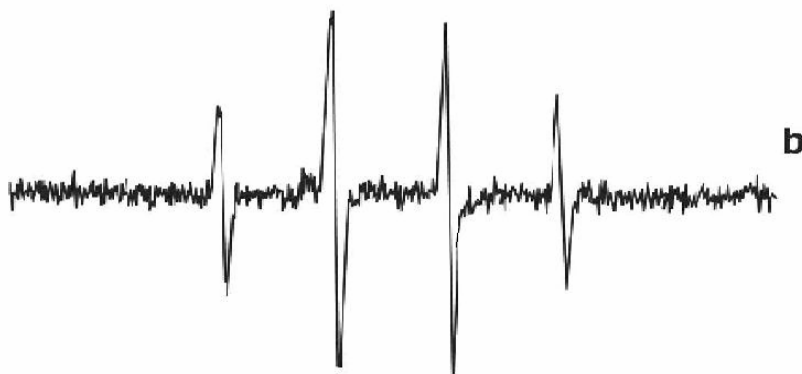

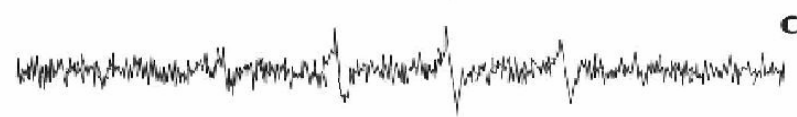

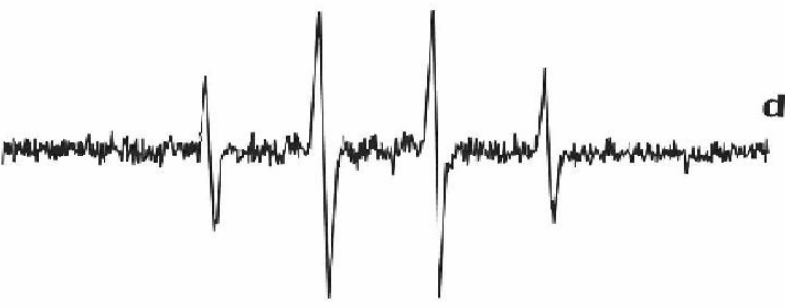

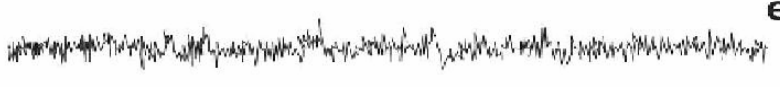

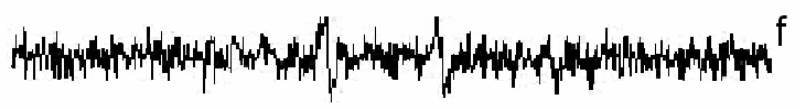

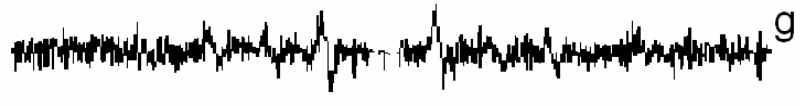

$\begin{array}{ccccc}1 & 1 & 1 & 1 & 1 \\ 3440 & 3460 & 3480 & 3500 & \substack{3520 \\ \text { Gauss }}\end{array}$

B)

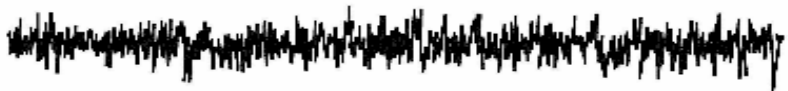

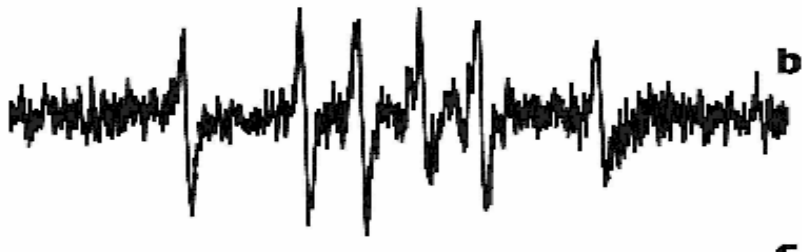

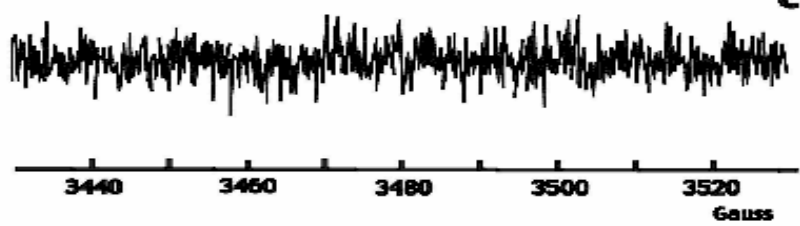

Fig.5 A) ESR spectra of a $10 \mu \mathrm{M}$ solution of PPME in presence of DMPO $(50 \mathrm{mM})$ in DMPC liposomes: a. before irradiation, b. after $6 \mathrm{~min}$ irradiation, c. after 6 min irradiation in presence of sodium benzoate $(0.1$ M), d. after 6 min irradiation in presence of ADPA $(75 \mu \mathrm{M})$, e. after 6 min irradiation in presence of sodium benzoate $(0.1 \mathrm{M})$, ADPA $(75 \mu \mathrm{M})$ and DMA $(0.6 \mathrm{mM})$, f. after $6 \mathrm{~min}$ irradiation in presence of SOD $(200 \mathrm{U} / \mathrm{ml}), \mathrm{g}$. after 6 min irradiation in presence of desferrioxamine $(500 \mu \mathrm{M})$. B) ESR spectra of a $10 \mu \mathrm{M}$ solution of PPME in presence of DMPO $(50 \mathrm{mM})$ in phosphate buffer $\mathrm{pH}$ 7: ethanol mixture (80\%:20\%) : a. in the absence of irradiation, b. after $6 \mathrm{~min}$ irradiation, c. after $6 \mathrm{~min}$ irradiation in presence of sodium benzoate $(0.5 \mathrm{M})$. 
DMA (0.6 mM,) no ESR signal was observed. The addition of SOD (a specific $\mathrm{O}_{2}^{-\bullet}$ scavenger, $200 \mathrm{U} / \mathrm{ml}$ ) and desferrioxamine (a highly $\mathrm{Fe}^{3+}$ chelator, $0.5 \mathrm{mM}$ ) to the solution before the 5 cycles of freezing-unfreezing induced strong decrease of the signal (around $75 \%$, data not shown).

As shown in Fig. 5B, a typical ESR spectrum of DMPOhydroxyethyl radical adducts $\left(\mathrm{a}^{\mathrm{N}}=15.8 \mathrm{G}, \mathrm{a}^{\mathrm{H}}=22.8 \mathrm{G}\right)$ was obtained after PPME irradiation for $6 \mathrm{~min}$ in phosphate buffer $\mathrm{pH} 7$ in presence of $20 \%$ of ethanol and $50 \mathrm{mM}$ of DMPO. Adding $0.5 \mathrm{M}$ sodium benzoate, SOD (200 U/ ml) or desferrioxamine decreased the ESR signal intensity. Moreover, the irradiation of PPME for $10 \mathrm{~min}$ in phosphate buffer $\mathrm{pH} 7$ in the presence of $20 \%$ of ethanol and $10 \mathrm{mM}$ of 4-oxo-TEMP, a specific ${ }^{1} \mathrm{O}_{2}$ spin trap, abolished the ESR signal (data not shown). The ESR error was estimated about $10 \%$.

\section{Singlet oxygen production during PPME irradiation}

The value of singlet oxygen quantum yield $\left(\Phi^{\mathrm{PPME}}\left({ }^{1} \mathrm{O}_{2}\right)\right)$ was determined in ethanol, liposomes and PBS. The ${ }^{1} \mathrm{O}_{2}$-scavenger used was DMA for solubilization in ethanol and DMPC liposomes and ADPA for PBS solutions.

$\Phi^{\mathrm{PPME}}\left({ }^{1} \mathrm{O}_{2}\right)$ in ethanol was obtained by comparing the decay slopes of DMA in the presence of photoexcited PPME to the decay slope in the presence of $\mathrm{RB}^{39}$ (Fig.6A) as described in section Materials and methods. The kinetics was of first order (Fig. 6A) confirming that ${ }^{1} \mathrm{O}_{2}$ is predominantly deactived by the solvent. The $\Phi^{\mathrm{PPME}}\left(\mathrm{O}_{2}\right)$ was found to be 0.2 (with a relative error of $10 \%$ ).

In order to ascertain that DMA absorbance decay during PPME irradiation was only due to the reaction of DMA with ${ }^{1} \mathrm{O}_{2}, \mathrm{NaN}_{3}$, another ${ }^{1} \mathrm{O}_{2}$ quencher, was added to the solution of PPME and DMA. The ratio of the rate constant of DMA disappearance with or without $\mathrm{NaN}_{3}$, named respectively $\mathrm{k}$ and k', followed the Stern-Volmer equation :

$$
\frac{\mathrm{k}}{\mathrm{k}^{\prime}}=1+\frac{\mathrm{k}_{\mathrm{N}}}{\mathrm{k}_{\mathrm{d}}\left[\mathrm{NaN}_{3}\right]}
$$

Complete quenching was observed for a $\mathrm{NaN}_{3}$ concentration of 8 $\mathrm{mM}$ (data not shown) and the rate constant $\mathrm{k}_{\mathrm{N}}$ of the reaction between $\mathrm{NaN}_{3}$ and ${ }^{1} \mathrm{O}_{2}$ was found to be $1.5 \times 10^{8} \mathrm{M}^{-1} \mathrm{~cm}^{-1}$, a value in agreement with the value found in the literature $(2.2 \mathrm{x}$ $\left.10^{8} \mathrm{~m}^{-1} \mathrm{~s}^{-1}\right)^{44}$

The incorporation of a photosensitizer in the lipidic bilayer of liposomes enhanced the singlet oxygen quantum yield ${ }^{39}$. Because of diffusion, the rate of ${ }^{1} \mathrm{O}_{2}$ deactivation by the solvent, $\mathrm{k}_{\mathrm{d}}$, must take into account the heterogeneity of the environment ${ }^{45,46}$. To find $\mathrm{g}^{\mathrm{H}_{2} \mathrm{O}}$ and $\mathrm{g}^{\mathrm{v}}$, we changed the nature of the solvent to induce a variation of the isotopic lifetime ${ }^{39}$. Phosphate buffer was replaced by deuterium oxide $\left(\mathrm{D}_{2} \mathrm{O}\right.$, Fig. $6 B$ ). The ratio of the rates of DMA destruction in $\mathrm{H}_{2} \mathrm{O}$ and $\mathrm{D}_{2} \mathrm{O}$ was measured to be equal 2.8. This experimental value can be related to the weighting factor by the equation :

$$
\frac{\mathrm{g}^{\mathrm{H}_{2} \mathrm{O}} \mathrm{k}_{\mathrm{d}}^{\mathrm{D}_{2} \mathrm{O}}+\mathrm{g}^{\mathrm{v}} \mathrm{k}_{\mathrm{d}}^{\mathrm{v}}}{\mathrm{g}^{\mathrm{H}_{2} \mathrm{O}} \mathrm{k}_{\mathrm{d}}^{\mathrm{H}_{2} \mathrm{O}}+\mathrm{g}^{\mathrm{v}} \mathrm{k}_{\mathrm{d}}^{\mathrm{v}}}=2.8
$$

where $\mathrm{k}_{\mathrm{d}}{ }_{\mathrm{H}} \mathrm{O}=2.5 \times 10^{5} \mathrm{~s}^{-1}, \mathrm{k}_{\mathrm{d}}^{\mathrm{v}}=4 \times 10^{4} \mathrm{~s}^{-1},{ }^{47}, \mathrm{k}_{\mathrm{d}} \mathrm{D}_{2} \mathrm{O}=1.8 \times 10^{4} \mathrm{~s}^{-1}$. Taking into account that $\mathrm{g}^{\mathrm{H}_{2} \mathrm{O}}+\mathrm{g}^{\mathrm{v}}=1$, it can be found that $\mathrm{g}^{\mathrm{H}_{2} \mathrm{O}}$ $=0.28$ and $\mathrm{g}^{\mathrm{v}}=0.72$. This value is characteristic of $\mathrm{a}$ photosensitiser embedded in the lipidic bilayer.

In the same way than in ethanol, the addition of $\mathrm{NaN}_{3}$, in the aqueous solution outside liposomes, quenched the DMA consumption (data not shown).
A)

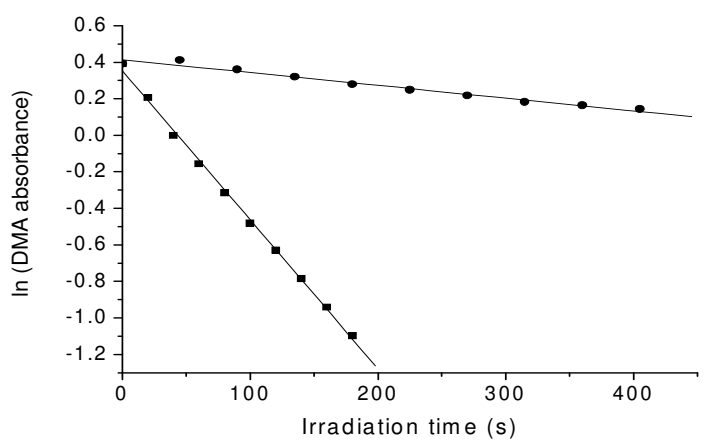

B)

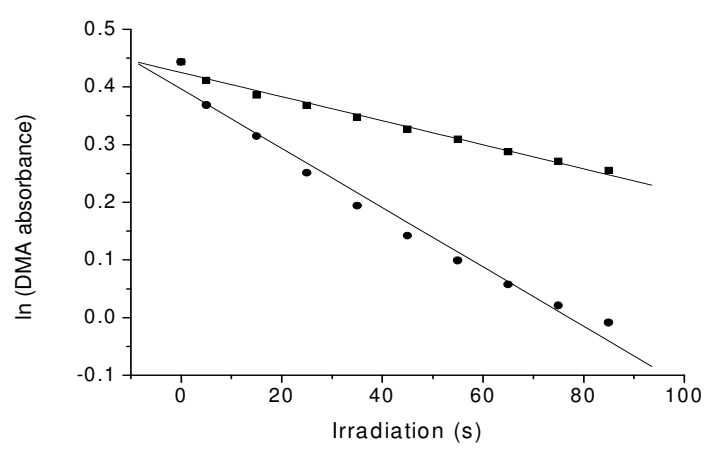

C)

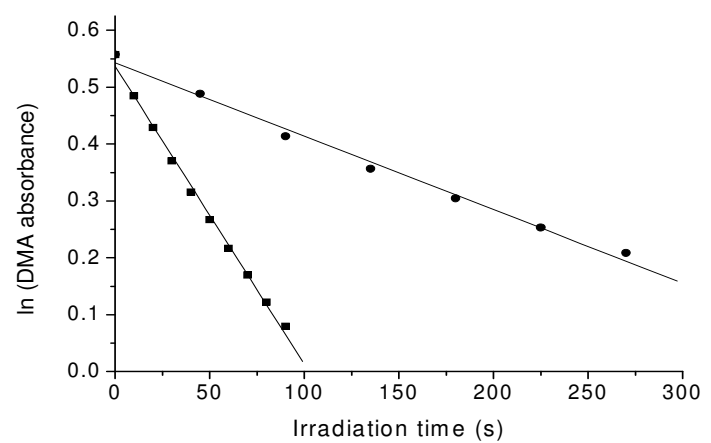

Fig.6 A. Evolution in ethanol of DMA absorbance at $398 \mathrm{~nm}$ in the presence of photoexcited PPME $(\bullet)$ and in the presence of photoexcited RB (•). B. Evolution of DMA absorbance at $402 \mathrm{~nm}$ in the presence of photoexcited PPME embedded in liposomes and solubilized in phosphate buffer $\mathrm{pH} 7(\bullet)$ and in deuterium oxide (-). C. Evolution of DMA absorbance at $402 \mathrm{~nm}$ in presence of photoexcited PPME in ethanol $(\bullet)$ and liposomes $(\mathbf{\bullet})$. $[\mathrm{DMA}]=$ $0.6 \mathrm{mM},[\mathrm{PPME}]=10 \mu \mathrm{M},[$ liposomes $]=7.38 \mathrm{mM}$.

Fig. 6C shows the loss of absorbance of DMA at $402 \mathrm{~nm}$ during the photosensitizing reaction mediated by PPME bound to liposomes and irradiated above $460 \mathrm{~nm}$. The $\Phi^{\mathrm{PPE}}\left({ }^{1} \mathrm{O}_{2}\right)$ in DMPC liposomes was found to be 0.13 using $\Phi^{\text {PPME }}\left({ }^{1} \mathrm{O}_{2}\right)$ in ethanol as a standard.

The irradiation of PPME in phosphate buffer did not modify the ADPA absorption spectrum (data not shown). We conclude that PPME in phosphate buffer did not produce any ${ }^{1} \mathrm{O}_{2}$.

\section{Laser flash photolysis study of PPME triplet state}

Laser flash photolysis of PPME in argon-flushed ethanol or water solutions was used to detect the tripet-state formation of the chromophore. The PPME was excited into Soret band at 355 nm.

Fig. 7A and 7C show respectively the differential absorption $(\triangle \mathrm{A})$ spectra of PPME in ethanol and DMPC liposomes recorded at the end of a laser pulse under anaerobic conditions. At any wavelength, the time evolution of the absorbance changes was 
monoexponential with lifetime of $35 \mu$ in ethanol and $15 \mu$ s in liposomes respectively.

While only triplet state was formed, the following technique was used. The dependence of the transient signal at $450 \mathrm{~nm}$ on the laser energy was linear up to an incident fluence of $4 \mathrm{mJcm}^{-2}$ in ethanol and $10 \mathrm{mJcm}^{-2}$ in liposomes. The monomeric character of the transient signal observed led us to assign this transient to the triplet state of PPME. This assignment was confirmed by the efficient quenching of the transient absorption in presence of oxygen with a rate constant controlled by the diffusion.

The triplet state absorption spectrum of PPME was determined by the approximation method described in $\mathrm{X}$. Damoiseau and $\mathrm{al}^{47}$ using $\mathrm{A}_{\mathrm{T}}=\Delta \mathrm{A}+\alpha \mathrm{A}_{0}$ with $\mathrm{A}_{\mathrm{T}}$, the triplet state absorbance ; $\mathrm{A}_{0}$, the ground state absorbance and $\alpha$ the fraction of ground state molecules coverted into triplet at time t. For different values of $\alpha$ tried, the resulting absolute absorption spectrum of the triplet was compared with that of the ground state of the dye. Under the assumption that the triplet absorption spectrum must be positive and different from that of the ground state, acceptable $\alpha$ values were found around 0.55 for PPME in ethanol and around 0.45 for PPME encapsulated in liposomes. Under these conditions, the triplet absorption coefficients of the dye were estimated with a relative error of $20 \%$. The triplet-state spectrum of PPME was characterized by two maxima at $390 \mathrm{~nm}$ and $660 \mathrm{~nm}$ for ethanol (Fig. 7B) and only one maximum at $390 \mathrm{~nm}$ for PPME in DMPC liposomes (Fig. 7D).

To determine $\Phi_{\mathrm{T}}{ }^{\mathrm{PPME}}$, the triplet absorption of anthracene and PPME were monitored at 422 and $450 \mathrm{~nm}$, respectively, their maxima corresponding to triplet excitation coefficient of 64700 $\mathrm{M}^{-1} \mathrm{~cm}^{-1}$ for anthacene and $14600 \mathrm{M}^{-1} \mathrm{~cm}^{-1}$ for PPME in ethanol. The triplet quantum yields of PPME, determined using a comparative methods ${ }^{35,36}$, were found to be 0.23 in ethanol and 0.15 in DMPC liposomes. No triplet state formation was observed by laser flash photolysis when PPME is solubilized in aqueous solution.

\section{DISCUSSION}

The photochemical properties of a photosensitizer, especially its absorption spectrum and its aggregation state, the efficiency of intersystem crossing to the triplet state and the quantum yield of ${ }^{1} \mathrm{O}_{2}$ influence the success of $\mathrm{PDT}^{5,48}$.

The aggregation process is, as previously observed for other sensitizers like Bacteriochlorin $\mathrm{a}^{39}$, associated with a decrease of singlet oxygen production. For PPME, $\Phi\left({ }^{1} \mathrm{O}_{2}\right)$ was about 0.2 in ethanol and 0.13 in liposomes while in PBS, where the dye was stongly aggregated, there was no detectable production of ${ }^{1} \mathrm{O}_{2}$. These results with singlet oxygen are consistent with the $\Phi_{\mathrm{T}}$ results $\left(\Phi_{\mathrm{T}}\right.$ was 0.23 and 0.15 respectively in ethanol and liposomes) and allow to conclude that almost all PPME triplet molecules reacted with oxygen to form singlet oxygen. This is a great advantage compared to other sensitizers like haematoporphyrin ${ }^{37}$. Indeed, haematoporphyrin is characterized by $\Phi_{\mathrm{T}}=0.63$, a value much higher than that obtained for PPME but $\Phi\left({ }^{1} \mathrm{O}_{2}\right)$ was only of 0.32 in $\mathrm{H}_{2} \mathrm{O}$. Moreover, we have shown that the ${ }^{1} \mathrm{O}_{2}$ production was improved in liposomes by comparison with aqueous solutions. This result is an important indication for PDT since ${ }^{1} \mathrm{O}_{2}$ is probably the main ROS involved in the mechanism of cell killing.

The ESR spin adduct generated by photoexcited PPME in liposomes and DMPO can be attributed to the DMPO-OH spin adduct. However, there are a number of potential sources for this signal other than freely diffusing $\mathrm{OH}^{*}$ trapping by $\mathrm{DMPO}^{49}$.Competition experiments must be carried out to choose between :

$$
\begin{aligned}
& \mathrm{DMPO}+\mathrm{O}_{2}^{--} \rightarrow \text { DMPO- }{ }^{-} \mathrm{OOH} \text { (lifetime of the adduct } 66 \mathrm{~s} \text { ) } \\
& \downarrow \mathrm{k}=10^{9} \mathrm{M}^{-1} \mathrm{~s}^{-1} \\
& \text { DMPO- }{ }^{\circ} \mathrm{OH}+\mathrm{OH}
\end{aligned}
$$$$
\mathrm{DMPO}+\mathrm{OH}^{\bullet} \rightarrow \mathrm{DMPO}-\mathrm{OH}^{\bullet}
$$

$$
\begin{aligned}
\mathrm{DMPO}+{ }^{1} \mathrm{O}_{2} \rightarrow\left[\mathrm{DMPO}^{1} \mathrm{O}_{2}\right] & \rightarrow \text { DMPO }-\mathrm{OH}^{\bullet}+\mathrm{OH}^{\bullet} \\
\mathrm{k} & =1.8 \times 10^{7} \mathrm{M}^{-1} \mathrm{~s}^{-1}
\end{aligned}
$$

A)

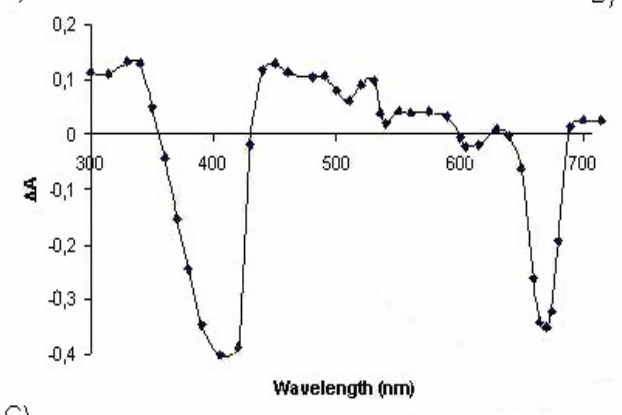

C)

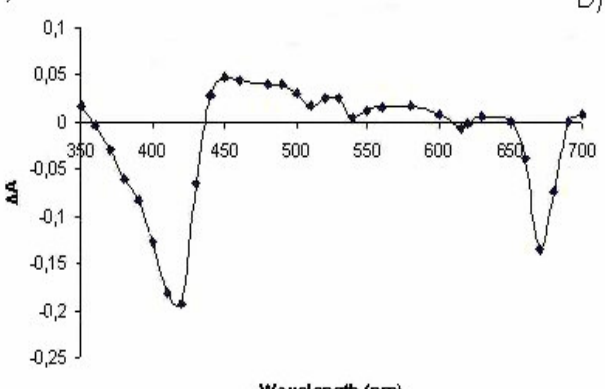

B)

D)
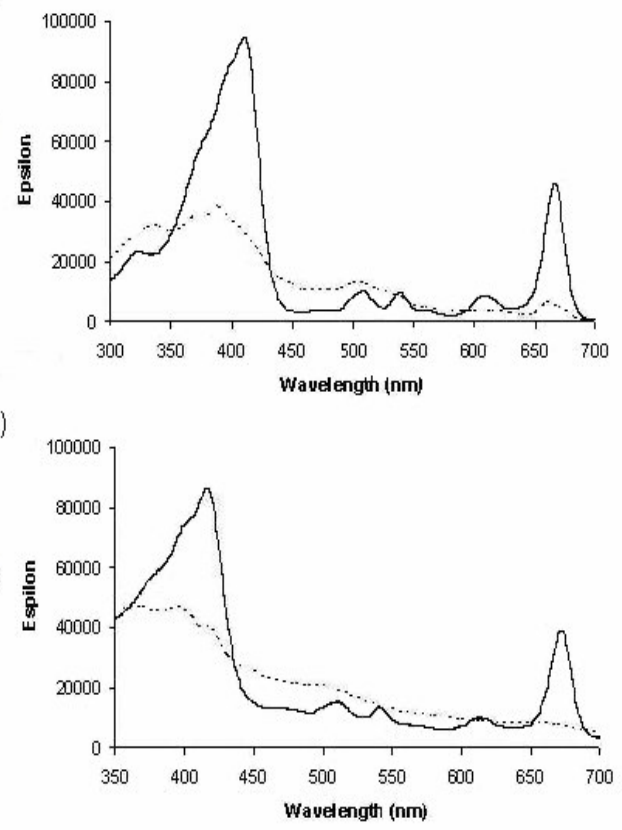

Fig.7 A) Differential absorption spectrum of an anaerobic PPME solution in ethanol $(20 \mu \mathrm{M})$ at the end of the laser pulse. B) Ground-state (-) and calculated tripet-state (dotted line) absorption spectra of PPME in ethanol $(20 \mu \mathrm{M})$. C) Differential absorption spectrum of an anaerobic PPME solution in liposomes $(10 \mu \mathrm{M})$ at the end of the laser pulse. D) Ground-state (-) and calculated tripet-state (dotted line) absorption spectra of PPME in liposomes $(10 \mu \mathrm{M}),[\mathrm{DMPC}]=7.376 \times 10^{-3} \mathrm{M}$. 
Competition experiments performed with sodium benzoate, an $\mathrm{OH}^{*}$ scavenger, showed that $74 \%$ of the DMPO-OH spin adduct signal observed in liposomes was due to trapping of $\mathrm{OH}^{*}$. The use of ${ }^{1} \mathrm{O}_{2}$ quenchers like ADPA and DMA showed that the remaining part of the signal must be attributed to the formation of a complex between ${ }^{1} \mathrm{O}_{2}$ and DMPO and its subsequent decay to DMPO- $\mathrm{OH}^{*}$ and free $\mathrm{OH}^{*}$. This latter result is in good agreement with the absorption measurements which show a non negligible ${ }^{1} \mathrm{O}_{2}$ production by photoexcited PPME in liposomes. Our ESR results in PBS confirmed the absence of ${ }^{1} \mathrm{O}_{2}$ production. Indeed, no Tempo signal resulting from the reaction between ${ }^{1} \mathrm{O}_{2}$ and Temp was observed. The only ESR signal observed was attributed to hydroxyethyl radicals resulting from the reaction of hydroxyl radicals and ethanol when DMPO was added to the PPME solution. It completely disappeared when sodium benzoate was added to the solution. This signal can be attributed to $\mathrm{OH}^{*}$ production after visible irradiation of PPME. Indeed, $\mathrm{OH}^{*}$ reacted with the ethanol present in the solution to form the hydroxyethyl radicals and then the corresponding DMPO adduct.

PPME like other pheophorbides a is characterized by an intense $\mathrm{S}_{0} \rightarrow \mathrm{S}_{1}$ electronic transition around $660 \mathrm{~nm}$, where the penetration depth of light into tissues is higher than at $630 \mathrm{~nm}$ (iradiation wavelength used in PDT with photofrin). Contrary to PPME, other monomeric derivatives of chlorophyll a and pheophorbides a has a $\Phi\left({ }^{1} \mathrm{O}_{2}\right)$ about $0.6^{37}$. The weak value of the $\Phi\left({ }^{1} \mathrm{O}_{2}\right)$ of PPME is probably due to $\mathrm{OH}^{\bullet}$ formed from PPME photoexcited perharps in its singlet state. Indeed, the mechanism of $\mathrm{OH}^{*}$ generation from photoexcited PPME could be the following because the SOD and desferrioxamine added to the solution reduced the ESR spectra of DMPO-OH ${ }^{*}$ adducts (HaberWeiss mechanism).

$$
\begin{aligned}
& \text { PPME }^{*}+\mathrm{O}_{2} \rightarrow \mathrm{PPME}^{++}+\mathrm{O}_{2}^{--} \\
& 2 \mathrm{O}_{2}^{--}+2 \mathrm{H}^{+} \rightarrow \mathrm{H}_{2} \mathrm{O}_{2}+\mathrm{O}_{2} \\
& \mathrm{Fe}^{3+}+\mathrm{O}_{2}^{--} \rightarrow \mathrm{Fe}^{2+}+\mathrm{O}_{2} \\
& \mathrm{Fe}^{2+}+\mathrm{H}_{2} \mathrm{O}_{2} \rightarrow \mathrm{Fe}^{3+}+\mathrm{OH}^{-}+\mathrm{OH}^{\cdot}
\end{aligned}
$$

Therefore, PPME does not act simply as a type II sensitizer. Moreover, Matroule et $\mathrm{al}^{12}$ have indicated that, in the case of PPME, ${ }^{1} \mathrm{O}_{2}$ was not the only species responsible for cell death. According to these authors, other ROS than ${ }^{1} \mathrm{O}_{2}$ are probably implicated in the apoptosis mechanism. Our ESR spin-trapping experiments showed unambiguously that photoexcited PPME was able to produce both $\mathrm{OH}^{*}$ and $\mathrm{O}_{2}^{-}$.

With regard to the essential role of ROS in PDT, this improvement of $\mathrm{OH}^{*}$ and ${ }^{1} \mathrm{O}_{2}$ formation is a potentially useful information for enhancing the therapeutic applications of PPME. Solubilization of PPME in liposomes inducing monomerization might be a way to improve its efficacy in PDT.

\section{ACKOWNLEDGEMENTS}

This work was supported by CGRI-CNRS-FNRS funds.

\section{ABBREVIATIONS}

ADPA, anthracene-9,10-diproprionic acid ; DMA, 9,10 dimethylanthracene; DMPC, dimyristoyl-L- $\alpha$ phosphatidylcholine; DMPO, 5,5-dimethyl-1-pyrroline-N-oxide ; DSA, n-doxyl stearic acids ; ESR, electron spin resonance ; $\mathrm{NaN}_{3}$, sodium azide ; ${ }^{1} \mathrm{O}_{2}$, singlet oxygen $; \mathrm{O}_{2}{ }^{-*}$, superoxide anion ; $\mathrm{OH}^{\bullet}$, hydroxyl radical ; 4-oxo-TEMP, 2,2,6,6tetramethyl-4-piperidone ; PBS, phosphate buffer ; PDT, photodynamic therapy ; PPME, pyropheophorbide-a methyl ester ; RB, Rose Bengal ; ROS, reactive oxygen species ; SOD, superoxide dismutase ; $\Phi\left({ }^{1} \mathrm{O}_{2}\right)$, oxygen quantum yield ; $\Phi_{\mathrm{T}}$, triplet state quantum yield.

\section{REFERENCES}

1. W. Haussman, Die sensibilisierende Wirkung des Hematoporphyrins, Biochem Z, 1911, 30, 276.

2. A. Jesionek \& V. H. Tappeiner, Zur Behandlung der Hautcarcinomit mit Fluorescierenden Stoffen, Muench. Med. Wochneshr, 1903, 47, 2042.

3. O. Raab, Über die Wirkung Fluoreszierenden Stoffen, Infusoria Z Biol., 1900, 39, 524.

4. W. H. Boehncke, W. Sterry \& R. Kaufmann, Treatment of psoriasis by topical photodynamic therapy with polychromatic light, Lancet, 1994, 343, 801.

5. J. M. McCaughan, Jr. Photodynamic therapy, Drugs Aging, 1999, 15, 49-68.

6. B. W. Henderson and T. J. Dougherty, How does photodynamic therapy work? Photochem. Photobiol., 1992, 55, 145-157.

7. S. S. Brody and M. Brody, Absorption properties of aggregated (dimeric) chlorophyll, Biochem. Biophys. Acta, 1961, 54, 495-505.

8. A. B. Segelman, I. K. Hagen, S. A. Chernomorsky, S.-Y. Lee, I. K. Gadi, K. Weadock and G. H. Sigel, Jr., Intracellular distribution of porphyrin-based photosensitizers in vitro cultured human bladder tumor cells., Proc. SPIE int. Soc. Opt. Eng., 1987, 1065, 197-204.

9. A. A. Krasnovsky, Jr., K. V. Neverov and S. YU. Egorov, Photophysical studies of pheophorbide a and pheophitin a. Phosphorescence and photosensitized singlet oxygen luminescence, J. Photochem. Photobiol. B. : Biology, 1990, 5, 245-254.

10. K. Iwai, Y. Ichihara and S. Kimura, Comparison of photodynamic effects and tumor localization among the derivatives of pheophorbide, Photochem. Photobiol., 1988, 10, 247-252.

11. R. K. Pandey, A. B. Sumlin, S. Constantine, M. Aoudla, W. R. Potter, D. A. Bellnier, B. W. Anderson, M. A. Rodgers, K. M. Smith and T. J. Dougherty, Alkyl ether analogs of chlorophyll-a derivatives: Part 1, Synthesis, photophysical properties and photodynamic efficacy, Photochem. Photobiol. 1996, 64(1), 194204.

12. J.-Y. Matroule, C. M Carthy, D. J. Granville, O. Jolois, D. W. C Hunt and J. Piette, Mechanism of colon cancer cell apoptosis mediated by pyropheophorbide-a methyl ester photosensitization, Oncogene, 2001, 20, 4070-4084.

13. X. Sun and W. N. Leung, Photodynamic therapy with Pyropheophorbide-a methyl ester in Human Lung Carcinoma Cancer Cell: Efficacy, Localization and Apoptosis, Photochem. Photobiol., 2002, 75(6), 644-651.

14. J.-Y. Matroule, G. Bonizzi, P. Morlière, N. Paillous, R. Santus, V. Bours and J. Piette, Pyropheophorbide-a methyl ester mediated photosensitization activates transcription Factor NF- $\mathrm{kB}$ through the Interleukin-1 receptor-dependent signaling pathway, J. Biol. Chem., 1999a, 274, 2988-3000.

15. J. D. Spiker and J. C. Bommer. Chlorophyll and related pigments as photosensitizers in biology and medecine. In chlorophyll (Edited by H. Scheer), 1991, pp. 1181-1207. CRC Press, Florida.

16. B. W. Henderson, D. A. Bellnier, W. R. Greco, A. Sharma, R. K. Pandey, L. A. Vanghan, K. R. Weishaupt and T. J. Dougherty, An in vitro quantitative structure-activity relationship for a congeneric series of pheophorbide derivatives as photosensitizers for photodynamic therapy, Cancer Res., 1997, 57, 4000-4007.

17. C. - W. Lin, Photodynamic therapy of malignant tumors - recent developments, Cancer cells, 1991, 3, 437-444.

18. T. J. Dougherty, B. W. Henderson, S. Schwaetz, W. J.Winkelman and R.L. Lipson, in Historical Perspective in Photodynamic Therapy, Basic Pinciples and Clinical Applications, ed. B. W. Henderson and T.J. Dougherty, Marcel Dekker Inc., 1992, pp. 1-19.

19. K. Berg, In The Fundamental Bases of Phototherapy, ed. H. Honigsmann, G. Jori and A. R. Young, OEMF, Milan, Italy, 1996, Mechanisms of the cell damage in photodynamic therapy.

20. G. P. Gurinovich, I. G. Zhakov, G. A. Kostenich, G. A. Kochubeev, M. V.Sarzhevskaya and A. A. Frolov, Singulet oxygen and cancer phototherapy, Vestn. Akad. Med. Nauk SSSR, 1987, 12, 24-30. 
21. M. Sodona, C. M. Krishna and P. Riesz, The role of singulet oxygen in the photohemolysis of red blood cells sensitized by phthalocyanines sulfonates, Photochem. Photobiol., 1987, 43, 691699.

22. C. S. Foote, Definition of type I and II photosensitized oxidation, Photochem. Photobiol., 1991, 54(5), 659.

23. T. H. Foster, R. S. Murant, R. G. Bryant, R. S. Knox, S. L. Gibson, R. Hief, Oxygen consumption and diffusion effects in photodynamics therapy, Radiat. Res, 1991,126, 296-303.

24. J. P. Henning, R. L. Fourier, J. A. Hampton, A transient mathematical model of oxygen depletion during photodynamic therapy, Radiat Res, 1995, 142, 221-226.

25. A. Baker, J. R. Kanofsky, Quenching of singlet oxygen by biomolecules from L1210 leukemia cells. Photochem, Photobiol. 1992, 55, 523-528.

26. J. R. Kanofsky, Quenching of singlet oxygen by human red cell ghosts, Photochem. Photobiol., 1991, 53, 93-99.

27. M. Ochsner-Bruderer, Zinc (II) - phtalocyanine, a photosensitizer for photodynamic therapy of tumours, Inaugural Dissertation, University of Basle, Basle, 1994.

28. C. S. Foote, Type I and type II mechanisms of photodynamic action, in : J. R. Heitz, K. R. Downul (Eds.), Light-activated Pesticides, American chemical society, Washington, DC, 1987, 22-38.

29. I. J. MacDonald, J. Morgan, D. A. Bellnier, G. M. Paszkiewicz, J. E. Whitaker, D. J. Litchfield and T. J. Dougherty, Subcellular localization patterns and their relationship to photodynamic activity of pyropheophorbide-a derivatives, Photochem. Photobiol., 1999, 70, 789-797.

30. F. Jiang, L. Lilge, J. Grenier, Y. Li, M. D. Wilson, M. Chopp, Photodynamic therapy of U87 glioma in nude rat using liposomedelivered photofrin, Lasers Surg. Med., 1998, 22, 74-80.

31. M. J.Hope, M. B. Bally, G. Web and P. R. Cullis, Production of large unilamellar vesicles by rapid extrusion procedure. Characterization of size distribution, trapped volume and ability to maintain a membrane potential, Biochem. Biophys. Acta, 1985, 812, 55-65.

32. L. Mayer, M. Hope and P. Cullis, Vesicles of variable sizes produced by rapid extrusion procedure, Biochem. Biophys. Acta, 1986, 858 161-168.

33. M. Hoebeke, X. Damoiseau, Hans J. Schuitmaker, A. Van de Vorst, Fluorescence, absorption and electron spin resonance study of bacteriochlorin a incorporation into membrane models, Biochimica and Biophysiqua Acta, 1999, 1420, 73-85.

34. M. Hoebeke, A. Seret, J. Piette and A. Van de Vorst, Destruction of Stearic Acid Nitroxyl Radicals mediated by photoexcited Merocyanine 540 in liposomal and micellar system, Biochemistry, 1993, 32, 2730-2736.

35. A. R. Al Rabaa, F. Tfibel, F. Mérola, P. Pernot and M.-P. FontaineAupart, Spectroscopic and photophysical study of anthryl probe: DNA binding and chiral recognition, J. Chem. Soc., Perkin Trans., 1999, 2, 341-351.

36. M.-P. Fontaine-Aupart, E. Renault, L. Brian, J. F. Delouis and M. Gardès-Albert, Triplet excited-state characterisation and determination of the photoionisation mechanism of the antitumoral drug pazelliptine, J. Photochem. Photobiol. A: Chem., 1995, 90, $95-$ 102.

37. R. V. Bensasson, E. J. Land and T. G. Truscott, Excitated States and Free Radicals in Biology and Medicine : Contributions from flash photolysis and pulse radiolysis, Oxford University Press, 1993.

38. R. V. Bensasson, E. J. Land and T. G. Truscott, Flash Photolysis and Pulse Radiolysis: Contributions to the Chemistry of Biology and Medicine, Pergamon Press, 1983.

39. M. Hoebeke and X. Damoiseau, Determination of the singlet oxygen quantum yield of bacteriochlorin a: a comparative study in phosphate buffer and aqueous dispersion of dimiristoyl-L- $\alpha$ phosphatidylcholine liposomes, Photochem. Photobiol. Sci., 2002, 1, 283-287.

40. E. Gandin, Y. Lion and A. Van de Vorst, Quantum yield of singulet oxygen production by Xanthene derivatives, Photochem. Photobiol., 1983, 37, 271-278.

41. I. Eichwurzel, H. Stiel and B. Röder, Photophysical studies of the pheophorbide a dimer, J. of Photoch. and Photobiol. B: Biology., 2000, 54 (2-3), 194-200.

42. A.-S. Fabiano, D. Allouche, Y.-H. Sanejouand and N. Paillous, Synthesis of a new cationic Pyropheophorbide derivate and studies of its aggregation process in aqueous solution, Photochem. Photobiol., 1997, 66(3), 336-345.

43 M. Hoebeke, H. J. Schuitmaker, L. E. Jannink, T. M. A. R. Dubbelman, A. Jakobs and A. Van de Vorst, Electron spin resonance evidence of the generation of superoxide Anion, Hydroxyl radical and singlet oxygen during the photohemolysis of human erythrocytes with bacteriochlorin a, Photochem. Photobiol., 1997, 66(4), 502-508.

44. M. A. Rubio, D. O. Martire, S. E. Braslavsky, E. A. Lissi, Influence of the ionic strength on $\mathrm{O}_{2}\left({ }^{1} \Delta \mathrm{g}\right)$ quenching by azide, J. Photochem. Photobiol., A, 1992, 66, 153-157.

45. M. Hoebeke, J. Piette and A. Van de Vost, Photosensitized production of singlet oxygen by merocyanine 540 bound to liposomes, J. Photochem. Photobiol. B: Biol, 1991, 9, 281-294.

46. S. Dearden, Kinetics of ${ }^{1} \mathrm{O}_{2}\left({ }^{1} \Delta_{\mathrm{g}}\right)$ photo-oxidation reactions in egg yolk lecithin vesicles, J. Chem. Soc., Faraday Trans. I, 1986, 82, 1627-1635.

47. X. Damoiseau, F. Tfibel, M. Hoebeke and M.-P. Fontaine-Aupart, Effect of aggregation on bacteriochlorin a triplet-state formation : a laser flash photolysis study, Photochem. Photobiol., 2002, 76(5), 480-485.

48. G. Jori, Tumor photosensitizers : approaches to enhance the selectivity and efficiency of photodynamic therapy, J. Photochem. Photobiol. B : Biol, 1996, 36, 87-93.

49. J. Feix and B. Kalyanaraman, Production of singlet oxygen-derived hydroxyl radical adducts during merocyanine-540 mediated photosensitization : analysis by ESR-spin trapping and HPLC with electrochimical detection, Arch. Biochem. Biophys., 1991, 15, 4351. 
